\title{
Investigating the impact of Lake Agassiz drainage routes on the 8.2 ka cold event with a climate model
}

\author{
Y.-X. Li ${ }^{1}$, H. Renssen ${ }^{2}$, A. P. Wiersma ${ }^{3}$, and T. E. Törnqvist ${ }^{1,4}$ \\ ${ }^{1}$ Department of Earth and Environmental Sciences, Tulane University, New Orleans, Louisiana 70118-5698, USA \\ ${ }^{2}$ Faculty of Earth and Life Sciences, VU University Amsterdam, Amsterdam, The Netherlands \\ ${ }^{3}$ Deltares, Subsurface and Groundwater Systems, Utrecht, The Netherlands \\ ${ }^{4}$ Tulane/Xavier Center for Bioenvironmental Research, Tulane University, New Orleans, Louisiana 70118-5698, USA
}

Received: 17 March 2009 - Published in Clim. Past Discuss.: 31 March 2009

Revised: 10 August 2009 - Accepted: 12 August 2009 - Published: 28 August 2009

\begin{abstract}
The $8.2 \mathrm{ka}$ event is the most prominent abrupt climate change in the Holocene and is often believed to result from catastrophic drainage of proglacial lakes Agassiz and Ojibway (LAO) that routed through the Hudson Bay and the Labrador Sea into the North Atlantic Ocean, and perturbed Atlantic meridional overturning circulation (MOC). One key assumption of this triggering mechanism is that the LAO freshwater drainage was dispersed over the Labrador Sea. Recent data, however, show no evidence of lowered $\delta^{18} \mathrm{O}$ values, indicative of low salinity, from the open Labrador Sea around $8.2 \mathrm{ka}$. Instead, negative $\delta^{18} \mathrm{O}$ anomalies are found close to the east coast of North America, extending as far south as Cape Hatteras, North Carolina, suggesting that the freshwater drainage may have been confined to a long stretch of continental shelf before fully mixing with North Atlantic Ocean water. Here we conduct a sensitivity study that examines the effects of a southerly drainage route on the $8.2 \mathrm{ka}$ event with the ECBilt-CLIO-VECODE model. Hosing experiments of four routing scenarios, where freshwater was introduced to the Labrador Sea in the northerly route and to three different locations along the southerly route, were performed to investigate the routing effects on model responses. The modeling results show that a southerly drainage route is possible but generally yields reduced climatic consequences in comparison to those of a northerly route. This finding implies that more freshwater would be required for a southerly route than for a northerly route to produce the same climate anomaly. The implicated large amount of LAO drainage for a southerly routing scenario is in line with a recent geophysical
\end{abstract}

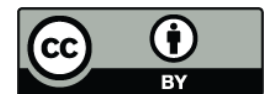

Correspondence to: $\mathrm{Y} . \mathrm{X} . \mathrm{Li}$ (li@tulane.edu) modelling study of gravitational effects on sea-level change associated with the $8.2 \mathrm{ka}$ event, which suggests that the volume of drainage might be larger than previously estimated.

\section{Introduction}

The $8.2 \mathrm{ka}$ cold event is the largest abrupt climate change over the past 10000 years documented in the Greenland ice core records (Alley et al., 1997; Kobashi et al., 2007). This event is characterized by a $\sim 160$ year-long cooling (Thomas et al., 2007) accompanied by dry and windy conditions in Greenland (Alley and Ágústsdóttir, 2005). Proxy records from many parts of the world, particularly the circum-North Atlantic region (e.g., Morrill and Jacobsen, 2005; Hughes et al., 2006; Kerschner et al., 2006; Lutz et al., 2007), suggest that this event has been broadly felt in the Northern Hemisphere. This large, abrupt, and widespread cooling event is often interpreted to result from the outburst of proglacial lakes Agassiz and Ojibway (LAO) that flooded the North Atlantic Ocean with freshwater. This would have slowed down Atlantic meridional overturning circulation (MOC), resulting in a reduction of poleward heat transport and widespread cooling (Barber et al., 1999). While far-field anomalies around $8.2 \mathrm{ka}$ may be compounded with the long-term climate variability driven by solar forcing (Rohling and Pälike, 2005), this causal mechanism gains support from both emerging proxy records and climate modeling data. High-resolution records from marine archives document rapid changes in both surface and deep oceans concomitant with the catastrophic drainage of LAO (Ellison et al., 2006; Kleiven et al., 2008). 
Early modeling work with a coupled ocean-atmosphere general circulation model has demonstrated that massive flux of surface freshwater to the North Atlantic Ocean can trigger rapid changes of the ocean-atmospheric system (Manabe and Stouffer, 1995). For the $8.2 \mathrm{ka}$ event, Renssen et al. (2001, 2002) first investigated model responses to freshwater forcing during early Holocene climate conditions with a global coupled atmosphere-sea ice-ocean model and showed that a pulse of freshwater perturbation can lead to a weakening of ocean circulation and an associated cooling anomaly consistent with proxy data around $8.2 \mathrm{ka}$. Bauer et al. (2004) simulated freshwater drainage scenarios with a coupled atmosphere-ocean-biosphere model and showed that a baseline freshwater flux is essential in reproducing climate anomalies around $8.2 \mathrm{ka}$. LeGrande et al. (2006) and LeGrande and Schmidt (2008) incorporated water isotope tracers in their model simulations and showed that modeled tracer responses are consistent with isotope-based proxy data of the $8.2 \mathrm{ka}$ event. Wiersma et al. (2006) examined various aspects of freshwater perturbations with an upgraded, global coupled atmosphere-ocean-sea ice model, and found that freshwater volume is a decisive factor in governing the characteristics of modeled anomalies. Comparison of model responses with proxy records (Wiersma and Renssen, 2006) supports the hypothesis that the $8.2 \mathrm{ka}$ event was triggered by an outburst of LAO.

In the previous modeling work, freshwater perturbations were introduced in either the Labrador Sea (e.g., Renssen et al., 2001, 2002; Wiersma et al., 2006) or Hudson Bay (e.g., LeGrande et al., 2006; LeGrande and Schmidt, 2008). In these studies, it is either implicitly assumed in an experiment design (perturbations introduced in the Labrador Sea) or intrinsically constructed in the models (perturbations introduced in the Hudson Bay) that LAO drainage was routed through the Hudson Strait, and then spread over the Labrador Sea before entering the North Atlantic Ocean. However, foraminiferal $\delta^{18} \mathrm{O}$ data from marine sediment cores from the Labrador Sea do not show the expected depleted $\delta^{18} \mathrm{O}$ values, indicative of low salinity, that appear to occur only on the Labrador shelf, south of the Newfoundland margin, and as far south as Cape Hatteras, North Carolina, between 8 and $9 \mathrm{ka}$ (Keigwin et al., 2005) (Fig. 1). In addition, detrital carbonate layers, representing the drainage event, do not occur across the Labrador Sea, but are mainly distributed along the Labrador shelf (Hillaire-Marcel et al., 2007). These data suggest that the final LAO drainage may not have spread over the Labrador Sea as often assumed, but perhaps occurred as a buoyant current flowing southeast along the coast reaching as far south as Cape Hatteras before fully mixing with North Atlantic Ocean water. The possible effects of a southerly routing of the LAO drainage on the $8.2 \mathrm{ka}$ event, as implied by oxygen-isotope data, has not yet been examined.

The objective of this study is to investigate the routing effects of LAO drainage on ocean circulation and the resulting climate changes around $8.2 \mathrm{ka}$ by introducing freshwater per-

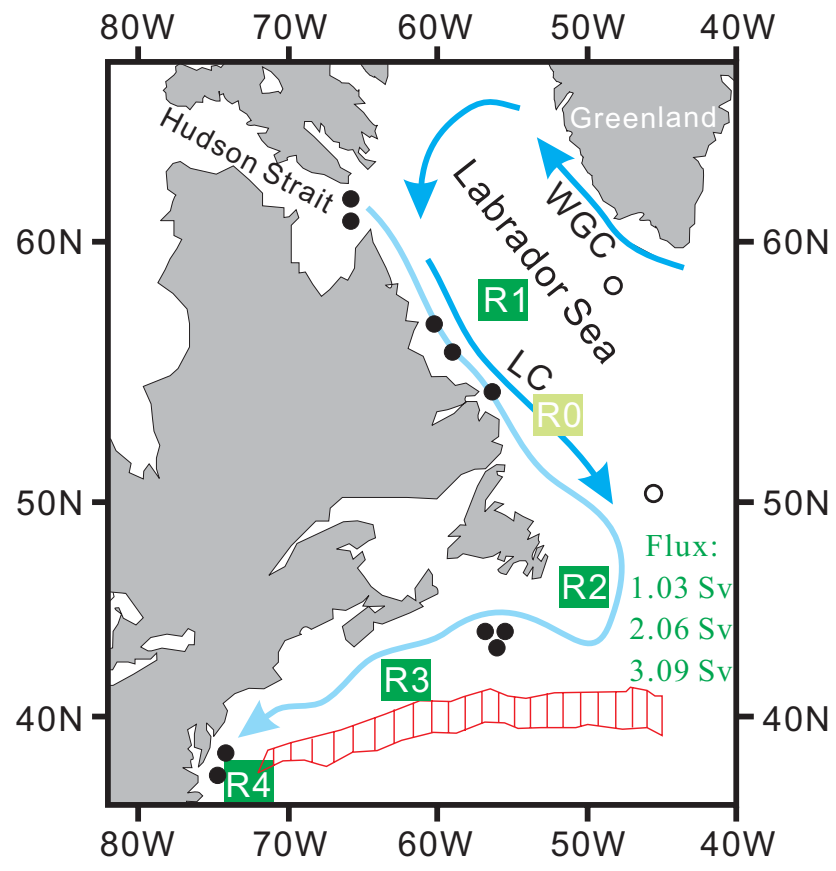

Fig. 1. Map showing schematic circulation of surface currents together with the location of high-resolution records of Holocene climate change in the northern North Atlantic Ocean (after Keigwin et al., 2005). Dots represent locations where low $\delta^{18} \mathrm{O}$ between about 8 and $9 \mathrm{ka}$ was documented. Open circles represent sites where no $\delta^{18} \mathrm{O}$ anomalies are observed. Sites are from Keigwin et al. (2005) and Hillaire-Marcel et al. (1994). The northern boundary of the present-day Gulf Stream (hatched area, its average position) is shown in red and is determined based on satellite observations (Lee, 1994). The model simulates a Gulf Stream at this position under present-day boundary conditions. In the early Holocene, the northern boundary of the modeled Gulf Stream is located further north at around $50^{\circ} \mathrm{N}$. Major cold currents are shown in dark blue. WGC $=$ West Greenland Current, $\mathrm{LC}=$ Labrador Current. The possible route of the freshwater drainage during the $8.2 \mathrm{ka}$ event is shown in light blue. Green areas with R1, R2, R3, R4 indicate the approximate locations where freshwater was introduced for the four different routing experiments. For each route, three freshwater flux scenarios were used. Light green area with R0 indicates the freshwater release site of Wiersma et al. (2006). Both R0 and R1 release freshwater directly into the Labrador Sea and are considered northerly routes; R2, R3, R4 are regarded as southerly routes.

turbations to both the Labrador Sea and three locations along the southerly drainage route. Investigating the routing effects of LAO drainage around $8.2 \mathrm{ka}$ could contribute to improved understanding of the cause of the $8.2 \mathrm{ka}$ climate event. 


\section{Methods}

\subsection{The ECBilt-CLIO-VECODE model}

We use the intermediate complexity Earth system model ECBilt-CLIO-VECODE (version 3) to investigate the routing effects of LAO drainage on Atlantic MOC and concomitant climatic responses. ECBilt-CLIO-VECODE is a threedimensional coupled atmosphere-ocean-vegetation model. The atmospheric component ECBilt is a spectral quasigeostrophic model that contains three vertical levels and has a T21 $\left(\sim 5.6^{\circ} \times 5.6^{\circ}\right)$ horizontal resolution (Opsteegh et al., 1998). The ocean component CLIO is a primitive-equation, free-surface ocean general circulation model coupled with a thermodynamic-dynamic sea-ice model. CLIO consists of 20 vertically unevenly spaced levels and has a $3^{\circ} \times 3^{\circ}$ horizontal resolution (Goosse and Fichefet, 1999). The terrestrial vegetation component VECODE takes into account evolution of vegetation cover that comprises trees, grasses, and desert (Brovkin et al., 2002).

The utility of this model has been demonstrated in several previous studies, showing that it can reproduce major characteristics of modern climate reasonably well under presentday forcing conditions (Goosse et al., 2001; Renssen et al., 2002). Also, this model has been frequently employed to investigate Holocene climate evolution (e.g., Renssen et al., 2005; Goosse et al., 2005) and abrupt climate changes such as the $8.2 \mathrm{ka}$ event (e.g., Renssen et al., 2001, 2002). In addition, the upgraded version 3 of this model can produce deep water formation in not only the Greenland-IcelandNorwegian (GIN) Sea, but also the Labrador Sea under modern climate conditions (Wiersma et al., 2006). This version of the model has been used to simulate freshwater forcing to ocean circulation and climate change around $8.2 \mathrm{ka}$ (Wiersma et al., 2006). A detailed description of the model can be found at http://www.knmi.nl/onderzk/CKO/ ecbilt.html.

Although the ocean component, CLIO, of this model does not have a horizontal resolution sufficient to characterize eddies which are important in mixing of freshwater and ocean water, a recent study demonstrates that responses of the coarse-resolution ECBilt-CLIO-VECODE model are largely similar to those of eddy-permitting resolution models (Spence et al., 2008). The coarse resolution of the model also prevents it from describing in detail the speculated southerly drainage, eastward and then southward along the North American coast. This means that the model cannot track freshwater drainage following a southerly route. However, a southerly drainage could be represented by introducing freshwater at a number of locations sequentially along a southerly drainage route. Therefore, despite these limitations, the ECBilt-CLIO-VECODE model can provide important insights into the impacts of routing effects on ocean circulation and climate change.

\subsection{Experimental setup and design}

Wiersma et al. (2006) examined various freshwater perturbation scenarios using version 3 of the ECBilt-CLIO-VECODE model for the $8.2 \mathrm{ka}$ climate event. In this previous study, freshwater was introduced over 5 years at a fixed location R0 (Fig. 1). The present study takes Wiersma et al.'s (2006) work a step further by investigating freshwater routing effects on ocean circulation and climate changes around $8.2 \mathrm{ka}$. Therefore, the experimental setup is the same as that of Wiersma et al. (2006) with greenhouse gas concentrations (Raynaud et al., 2000) and orbital parameters (Berger and Loutre, 1991) tuned to represent the conditions at $8.5 \mathrm{ka}$, and a baseline flow of $0.172 \mathrm{~Sv}$ introduced to the Labrador Sea to account for the background Laurentide Ice Sheet melting (Teller et al., 2002). The model with these boundary conditions was run for 850 years until it reaches quasiequilibrium in the deepest ocean layer, which is defined by $\mathrm{dT} / \mathrm{dt}<0.0002^{\circ} \mathrm{C} / 100 \mathrm{yr}$. Since a baseline flow is included, oceans are continuously freshening. Such an experimental design emulates the boundary conditions in the early Holocene when the Laurentide Ice Sheet was rapidly melting and sea level was rising. Therefore, the means of the quasi-equilibrium state prior to freshwater perturbation are used as the background conditions to which model responses are compared and thus represent the "control simulation" in this study.

To examine LAO routing effects, we perturbed the early Holocene climate system by introducing freshwater over a 5year period to the Labrador Sea, which represents a northerly routing scenario (R1), and to three other locations along the southerly drainage route near Grand Banks (R2), Georges Bank (R3), and Cape Hatteras (R4) (Fig. 1). At each location, freshwater is released to one grid cell at that site. After the 5-year freshwater perturbation, the model run continues for 500 years or more with a baseline flow at the exact same location and rate as for the pre-perturbation state. Such an experimental design that holds both initial and boundary conditions constant permits the evaluation of the sensitivity of the climate system to changes in the location of freshwater perturbations. The model responses to these four freshwater perturbation scenarios are therefore compared to examine the routing effects of LAO drainage on the early Holocene climate.

Wiersma et al. (2006) showed that the volume of freshwater introduced is a decisive factor affecting model responses. We therefore examine the persistency of model responses related to routing effects, if any, by introducing varying amounts of freshwater. Specifically, we designed three sets of experiments with an amount of freshwater introduced of $1.6 \times 10^{14} \mathrm{~m}^{3}(0.45 \mathrm{~m}$ sea-level equivalent, SLE), $3.2 \times 10^{14} \mathrm{~m}^{3}(0.90 \mathrm{~m} \mathrm{SLE})$, and $4.8 \times 10^{14} \mathrm{~m}^{3}$ (1.35 $\left.\mathrm{m} \mathrm{SLE}\right)$, over a 5 -year period, corresponding to a freshwater flux of $1.03 \mathrm{~Sv}, 2.06 \mathrm{~Sv}$, and $3.09 \mathrm{~Sv}$, respectively. For a given amount of freshwater introduced, simulations of the four 

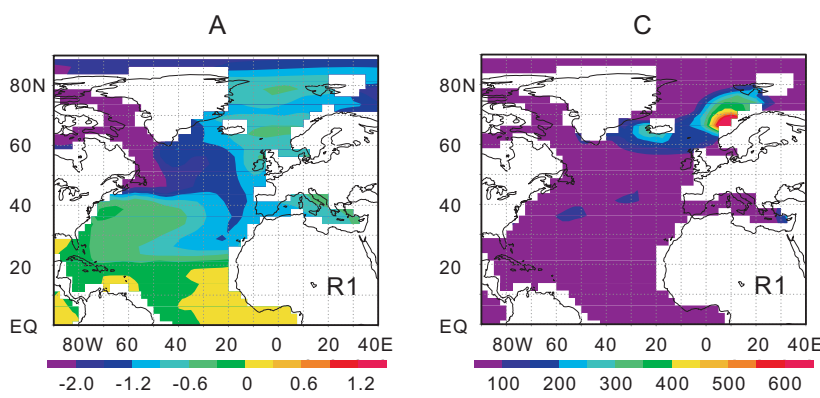

B
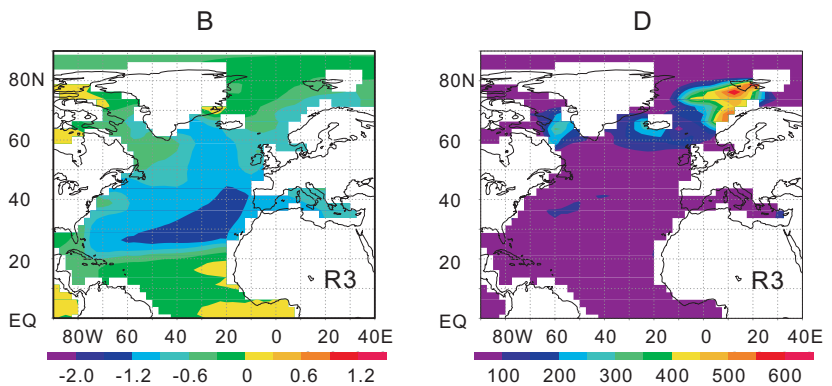

Fig. 2. February mean salinity anomalies (psu) (A, B) and convection depth $(\mathrm{m})(\mathbf{C}, \mathbf{D})$ over 20 years following the $2.06 \mathrm{~Sv}$ freshwater perturbation for R1 and R3. The salinity anomaly is defined as the 20 year mean salinity minus the salinity in the control simulation.

different routes (R1, R2, R3, and R4) of freshwater perturbation were performed. The amounts of freshwater used in this study are similar to those of single-, double-, and triplevolume freshwater used in Wiersma et al. (2006).

\section{Results}

\subsection{Oceanic responses}

The three southerly routes $\mathrm{R} 2, \mathrm{R} 3$, and R4 yield, by and large, similar model responses, and thus the results of R3 are henceforth presented as representative model responses of a southerly routing scenario. The northerly $\mathrm{R} 1$ route produces stronger anomalies than the southerly $\mathrm{R} 3$ route as evidenced by its more pronounced decrease in sea surface salinity (Fig. 2a, b) and the shutdown of convection in the Labrador Sea following the freshwater perturbation (Fig. 2c, d). The distinct oceanic responses to the R1 and R3 routes are also characterized by marked decreases in the strength of MOC in the North Atlantic Ocean (Fig. 3a), the GIN Sea (Fig. 3b), and meridional heat transport in the ocean at $30^{\circ} \mathrm{S}$ (Fig. 3c). The anomalies in these parameters become more pronounced as the freshwater flux increases from $1.03 \mathrm{~Sv}$, through 2.06 Sv, to 3.09 Sv (Fig. 3). For instance, the Atlantic MOC strength of $\mathrm{R} 1$ route decreases by $\sim 5 \mathrm{~Sv}, 8 \mathrm{~Sv}$, and $10 \mathrm{~Sv}$ for the $1.03 \mathrm{~Sv}, 2.06 \mathrm{~Sv}$, and $3.09 \mathrm{~Sv}$ freshwater perturbation, respectively (Fig. 3a).
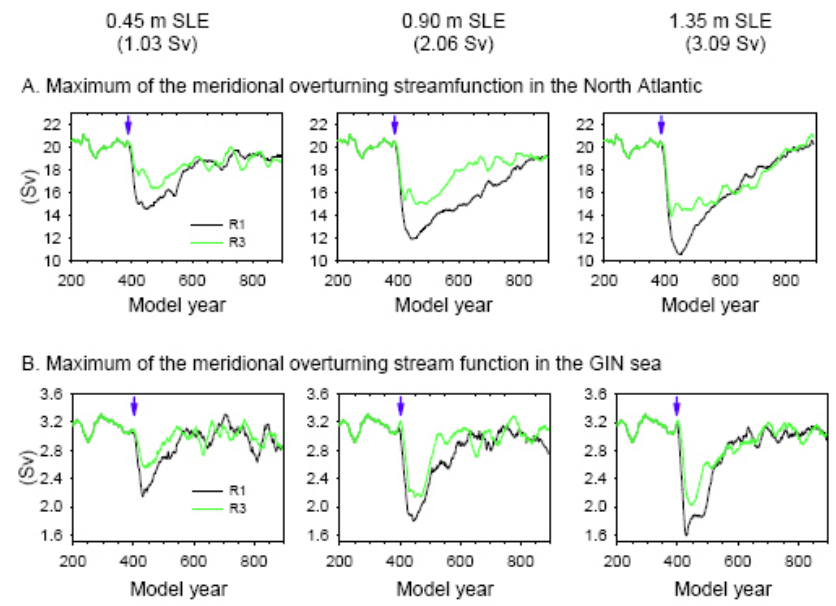

C. Meridional heat transport in the ocean at $30^{\circ} \mathrm{S}$

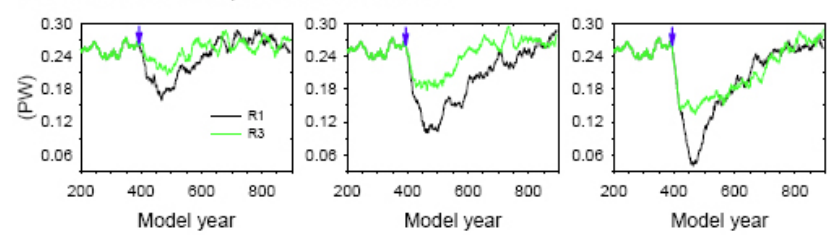

Fig. 3. Time series of maximum overturning stream function (Sv) in the North Atlantic (A) and the GIN Sea (B), and meridional heat transport in the ocean at $30^{\circ} \mathrm{S}(\mathbf{C})$. Left, middle, and right columns are results for $0.45 \mathrm{~m} \mathrm{SLE}, 0.90 \mathrm{~m} \mathrm{SLE}$, and $1.35 \mathrm{~m}$ SLE freshwater perturbation, respectively. All time series are smoothed by 25 -year running means. Arrows mark the time when the freshwater perturbation is introduced.

Overall, the duration of these anomalies, defined as the departure from the mean minus one standard deviation of the 200-year pre-perturbation values, also appears to increase with the increasing volume of freshwater introduced, though not as pronounced as the trend shown by the amplitudes of these anomalies among these three sets of experiments. For example, the MOC anomalies of R1 in the GIN Sea last for about 150 years, 200 years, and 250 years for the $0.45 \mathrm{~m}$ SLE, $0.90 \mathrm{~m} \mathrm{SLE}$, and $1.35 \mathrm{~m}$ SLE freshwater perturbations, respectively (Fig. 3b). Within all of the three sets of freshwater perturbation experiments, the northerly route R1 produces the larger anomalies than the southerly R3 route (Fig. 3). Overall, durations of the anomalies produced by the $\mathrm{R} 1$ route tend to be longer than those produced by the R3 route. Since the oceanic responses to different routes in each of the three sets of freshwater perturbation experiments show overall similar patterns of variation, we chose the $0.90 \mathrm{~m}$ SLE perturbation experiments as a representative set for further detailed examination of routing effects in the rest of this paper, unless stated otherwise.

Freshwater perturbation through the R1 route causes termination of deepwater formation in the Labrador Sea, while convective activity in the GIN Sea continues, though weaker in magnitude (Fig. 4a, b, c). For the southerly routes, 

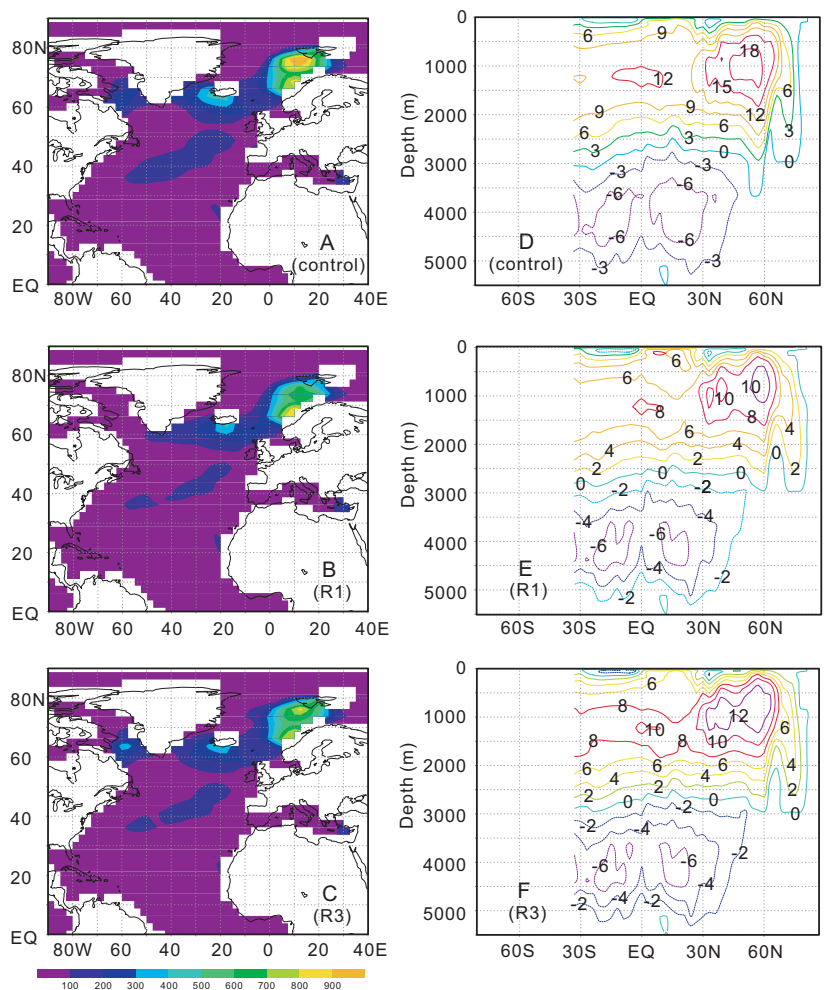

Fig. 4. The mean convection depth in February and stream function for the control simulation $(\mathbf{A}, \mathbf{D})$ and for the R1 (B, E), and R3 (C, F) simulations over 80 years following the freshwater perturbation. The flux of freshwater introduced is $2.06 \mathrm{~Sv}$.

convective activities in both the Labrador Sea and the GIN Sea remain but the GIN Sea deep convection appears to exhibit more strength than that for the northerly R1 route (Fig. 4b, c). In response to freshwater perturbations, the maximum of the meridional overturning stream function decreases from $18 \mathrm{~Sv}$ to $10 \mathrm{~Sv}$ for the R1 route and from $18 \mathrm{~Sv}$ to $12 \mathrm{~Sv}$ for the $\mathrm{R} 3$ route (Fig. $4 \mathrm{~d}, \mathrm{e}, \mathrm{f}$ ).

Freshwater perturbations lead to expansion of sea ice for all four routes. The $\mathrm{R} 1$ route causes the largest sea-ice expansion covering the entire Labrador Sea by the end of the freshwater perturbation, while the three southerly routing scenarios only lead to a slight sea-ice expansion over the Labrador Sea (not shown). Figure 5 shows that routes R1, R2, R3, and $\mathrm{R} 4$ lead to a maximum sea-ice expansion of $12.7 \times, 12.2 \times$, $12.1 \times$, and $12.0 \times 10^{12} \mathrm{~m}^{2}$, respectively. Sea-ice expansion of the $\mathrm{R} 1$ route also lasts longer than for the other three routes (Fig. 5). Also, R1 appears to trigger an immediate and rapid sea-ice expansion, while sea-ice expansion for R2, R3, and R4 starts about 20 or 30 years after the freshwater perturbation. In addition, it appears that the further south the site is located, the later the initiation of sea-ice expansion occurs (Fig. 5).

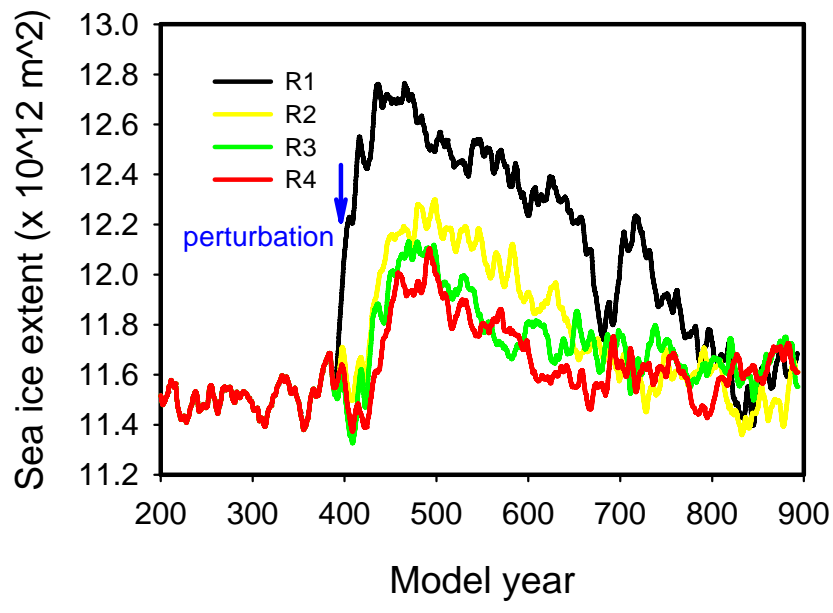

Fig. 5. Changes in sea-ice extent in the Northern Hemisphere after the freshwater perturbations for the northerly R1 and southerly R2, $\mathrm{R} 3$, and R4 routing scenarios. The time series are smoothed by $25-$ year running means for a $0.90 \mathrm{~m} \mathrm{SLE}$ freshwater perturbation over 5 years $(2.06 \mathrm{~Sv}$ flux).

\subsection{Atmospheric responses}

Both northerly and southerly routes of freshwater release lead to widespread cooling (Fig. 6a, b, c). To further evaluate the modeled atmospheric response to the perturbation scenarios, we analyzed the simulated air temperature at two locations: Greenland Summit and Ammersee, Central Europe. Both sites have well-established proxy records of the 8.2 ka event (e.g., Alley et al., 1997; Kobashi et al., 2007; von Grafenstein et al., 1998) (Fig. 6d). For the northerly R1 route, the maximum modeled temperature drop at Greenland Summit is about $2.5^{\circ} \mathrm{C}$ (Fig. 6e), which is comparable to the reconstructed $3.3^{\circ} \mathrm{C}$ of Kobashi et al. (2007), while simulations for Central Europe exhibit a maximum temperature drop of only about $0.8^{\circ} \mathrm{C}$ (Fig. 6f), which is about half of the reconstructed $1.5^{\circ} \mathrm{C}$ drop for the Ammersee (von Grafenstein et al., 1998). Both at Greenland Summit and in Central Europe, the R1 route leads to more pronounced temperature anomalies than does the southerly route, which is evidenced by its comparatively larger amplitude and longer duration (300 to 400 years) (Fig. 6e, f). The temperature anomalies produced by the southerly routes (e.g., R3) display similar patterns of variation with comparable magnitudes at both Greenland and Ammersee sites. The temperature change in Greenland is characterized by a brief warming, probably due to local and temporary intensification of convective activity (see Sect. 4.1), followed by a $\sim 200$ year cooling at Greenland Summit (Fig. 6e). The temperature in Central Europe exhibits a $\sim 100$ year weak cooling in response to the freshwater perturbation (Fig. 6f). 


\section{Discussion}

Our model responses exhibit overall similar variation patterns to those of Wiersma et al. (2006) (Fig. 7). The model experiments show that larger freshwater perturbations lead to more pronounced MOC anomalies, characterized by larger amplitudes and longer durations (Fig. 3a). These results corroborate the findings by Wiersma et al. (2006) that the volume of freshwater introduced is the premier factor affecting the MOC and corresponding climate anomalies. For a given freshwater perturbation, a northerly route (R1) appears to produce distinctively stronger responses than a southerly route (R3) (Figs. 3, 6). This is also true when the R1-induced anomaly is compared with that of R0 of Wiersma et al. (2006) (Fig. 7). The three southerly routes often yield largely similar anomalies in terms of amplitude and duration, yet show a tendency that anomalies become weaker as sites of freshwater perturbation are located farther south. Overall, these two features appear to be persistently present regardless of the exact amount of freshwater introduced (Fig. 3), and are thus considered to be robust. Therefore, these two features are regarded as consequences caused by different routes and are discussed below in detail.

\subsection{Comparing model results for northerly vs. southerly routes}

The northerly route (R1) produces distinctively stronger and often longer anomalies than the southerly routes in response to freshwater perturbations (Figs. 3, 6). The distinct difference between the northerly and the southerly routes must be related to the degree to which deep convection in the Labrador Sea and the GIN Sea is affected. The convection depth data show a marked difference between the northerly route and the southerly routing scenarios (Fig. 4). The $\mathrm{R} 1$ route leads to disappearance of deep convection in the Labrador Sea and subdued deep convection in the GIN Sea. The southerly routes show slightly stronger and more expanded deepwater formation in the GIN Sea than the R1 route. In comparison to the $\mathrm{R} 1$ scenario, some convective activity occurs in the Labrador Sea, though very weak, in all southerly routes.

The strong perturbation to the ocean and atmosphere in the R1 scenario may primarily result from the shutdown of deepwater formation in the Labrador Sea. The mean sea surface salinity in the Labrador Sea over 20 years following the freshwater perturbation drops more than 2 psu for the R1 route and only $\sim 0.5 \mathrm{psu}$ for the southerly R3 route (Fig. 2a, b). The intense freshening prevents deepwater formation in the Labrador Sea and leads to pronounced anomalies in the R1 scenario. The southerly routes cause only minor freshening in the Labrador Sea due to dilution and thus their effective forcing to ocean circulation is much smaller. As a result, anomalies produced by southerly routes are weaker than those of the northerly $\mathrm{R} 1$ route. The difference in the
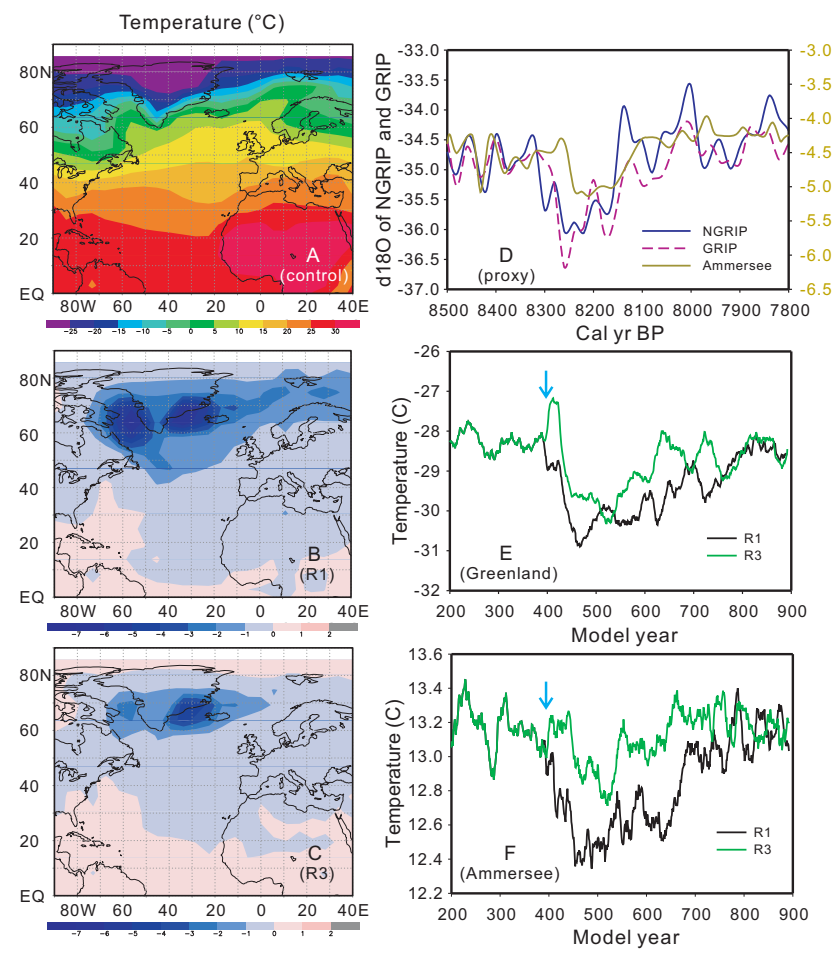

Fig. 6. Atmospheric responses to $2.06 \mathrm{~Sv}$ freshwater perturbations of the R1 and R3 routes. (A) shows the annual mean surface air temperature distribution of the control simulation and temperature anomalies caused by $\mathrm{R} 1$ and $\mathrm{R} 3$ routes are shown in (B) and (C), respectively. The temperature anomalies are defined as the difference between $\mathrm{R} 1$ and $\mathrm{R} 3$ route-induced temperature response and the temperatures of the control simulation. (D) shows the temperature proxy data from the Greenland ice cores and Lake Ammersee, Germany (data from Rasmussen et al., 2006 and von Grafenstein et al., 1998) to which model responses for R1 and R3 routing experiments at these two locations $(\mathbf{E}, \mathbf{F})$ are compared. The time series in $\mathrm{E}$ and $\mathrm{F}$ are smoothed by 25 -year running means.

magnitude of the freshwater forcing between the northerly and southerly routes could also explain the distinct difference in the temperature anomalies at Greenland Summit and in Central Europe (Fig. 6). Since the freshwater release site for $\mathrm{R} 1$ is close to where deepwater formation takes place in the Labrador Sea and the freshwater anomaly appears to spread out quickly (Fig. 2), the R1 scenario causes more rapid, more dramatic and prolonged expansion of sea ice in the Northern Hemisphere than in the three southerly routes (Fig. 5). The weaker effective forcing of the southerly routes is evidenced by the fact that sea-ice expansion does not occur immediately following the freshwater perturbation, but instead starts a few decades later (Fig. 5). This delay effect probably indicates the time necessary for freshwater perturbations prescribed in a southerly route to be transmitted to the deepwater formation sites and to cause anomalies in model responses. Since sea ice acts as an insulator of heat flux between ocean and atmosphere, the more expanded sea-ice cover in the R1 


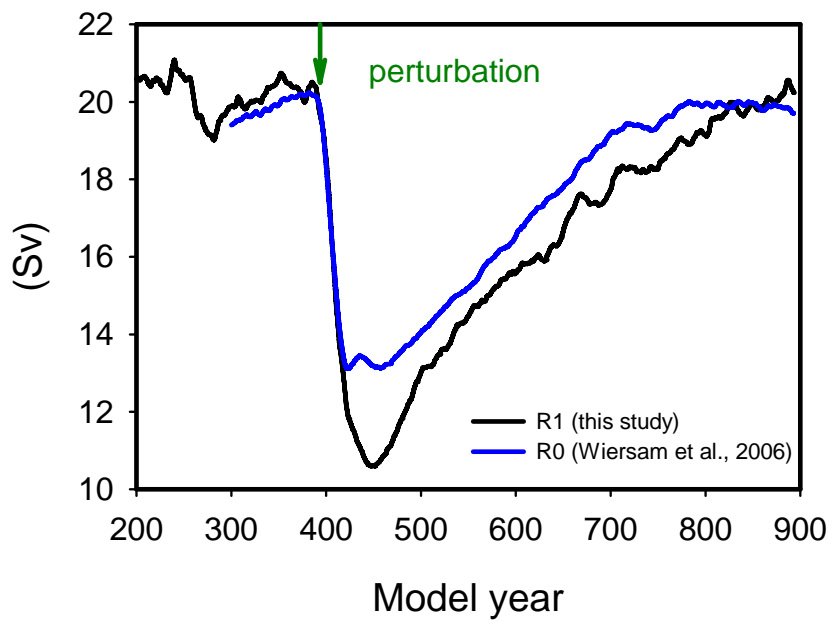

Fig. 7. Time series of maximum overturning stream function (Sv) in the Atlantic for a comparable freshwater perturbation of $3.09 \mathrm{~Sv}$ introduced at R1 (the present study) and R0 (Wiersma et al., 2006) (Fig. 1). The time series are smoothed by 25 -year running means. The arrow indicates the time when freshwater perturbation is introduced.

scenario could cause more effective reduction of heat flux from ocean to atmosphere. Together with the increase in surface albedo associated with expanded sea-ice cover, this leads to the more pronounced cooling than in the southerly routing scenarios (Fig. 6).

The different routes probably affect the deep convection in the GIN Sea in a similar fashion. The R1 route causes stronger anomalies in the GIN Sea than the southerly routes (Fig. 3b). The mean sea surface salinity over 20 years following the freshwater perturbation (Fig. 2a, b) shows that the freshwater anomaly in R1 appears to be more effectively transported to the GIN Sea via the North Atlantic drift than southerly routes where a comparatively larger fraction of the freshwater anomaly apparently dissipates southward (south of $40^{\circ} \mathrm{N}$ ) by gyres (Fig. 2a, b). The notable decrease in the MOC strength in the GIN Sea must also contribute to the more pronounced reduction in heat transport for the northerly route R1 than for a southerly routing scenario (Fig. 3c).

Atmospheric responses share the similarity with oceanic responses in that R1 route also causes larger and longer temperature anomalies than do the southerly routes (Fig. 6). This, again, is a consequence of the comparatively more effective impacts of the $\mathrm{R} 1$ route than southerly routes on convection in the Labrador Sea and the GIN Sea. One notably different feature is that atmospheric responses of the southerly route R3 display a brief warming preceding an expected cooling anomaly at Greenland Summit (Fig. 6e). Such a brief warming is not shown in proxy records (Fig. 6d) and is also absent from the atmospheric responses of the Ammersee site (Fig. 6f), suggesting that this short-lived warming is likely a local phenomenon. This brief warming over
Greenland is probably associated with a temporary and local intensification of convective activity near Iceland that compensates for local weakened deep convection near Svalbard, leading to local warming in the Iceland-Greenland region (Fig. 2). This convective activity near Iceland is short-lived due to the continued freshening of the surface ocean. The atmospheric response of R1 does not show such a short warming episode because freshwater forcing in R1 is most effective among all four routes, causing the GIN Sea to be relatively fresh (Fig. 2a, b), preventing deep convection to take place near Iceland. Therefore, the brief warming observed in the atmospheric responses of the southerly routes at Greenland Summit may not indicate important, regional changes in climate conditions.

\subsection{Comparing model results for the three southerly routes}

The three southerly routes yield similar model responses. While the magnitude and duration of the anomalies are largely comparable, anomalies tend to become weaker in magnitude and shorter in duration as the freshwater perturbation site moves farther south from R2 through R4 (Fig. 1). This pattern is most evident in the sea-ice data (Fig. 5) that show a decrease in the maximum of sea-ice extent and shortening in the duration of sea-ice expansion from route $\mathrm{R} 2$ through R4 (Fig. 5). In addition, the initiation of the seaice expansion appears to occur sequentially from route R2 through R4 (Fig. 5). The observed pattern may arise from the difference in the distance from the freshwater perturbation site to the deepwater formation site in the Labrador Sea. As the location at which freshwater is introduced is moved farther away (southward) from the deepwater formation site in the Labrador Sea, the effective freshwater forcing and the corresponding impacts on deep convection in the Labrador Sea weaken.

\subsection{Implications for the amount of LAO freshwater drainage}

Our modeling results show that a southerly route of freshwater forcing can produce a climate anomaly largely similar to that of a northerly route, but the anomaly is weaker in intensity and shorter in duration than that of a northerly route. Comparison of atmospheric responses to the $0.90 \mathrm{~m} \mathrm{SLE}$ freshwater forcing with proxy data from Greenland ice cores and Lake Ammersee sediments indicates that durations of the temperature anomalies of southerly routes better resemble those of proxy-based temperature anomalies than a northerly route (Fig. 6e, f). Therefore, our modeling results suggest that a southerly route is feasible and can explain the pattern of $\delta^{18} \mathrm{O}$ data from the Labrador Sea and its vicinity.

Since a southerly route produces a largely similar but weaker perturbation to the climate system than does a northerly route, this would imply that more freshwater would 
be required for a southerly route than a northerly routing scenario in order to produce a climatic anomaly similar to that of the $8.2 \mathrm{ka}$ event. Estimates of the amount of freshwater released from LAO drainage range widely from $\sim 1.2 \times 10^{14} \mathrm{~m}^{3}$ to $5.0 \times 10^{14} \mathrm{~m}^{3}$ (or $\sim 0.35 \mathrm{~m}$ to $1.5 \mathrm{~m} \mathrm{SLE}$ ) (De Vernal et al., 1997; Barber et al., 1999; Leverington et al., 2002; Von Grafenstein et al., 1998; Renssen et al., 2002). A sea-level study in the Mississippi Delta (Törnqvist et al., 2004) inferred an upper limit of $1.2 \pm 0.2 \mathrm{~m}$ for an abrupt sealevel rise associated with the LAO drainage. However, recent geophysical modeling suggests that the local sea-level rise in the Mississippi Delta only represents about a fifth of the eustatic sea-level rise resulting from LAO drainage, because the perturbation of the gravitational field would lead to a nonuniform pattern of sea-level change (Kendall et al., 2008). Hence, a larger amount of freshwater release than inferred by Törnqvist et al. (2004) remains a possibility. Our findings of a larger amount of drainage for a southerly routing scenario would thus be in line with these geophysical model results.

\subsection{Limitation of this study}

One important assumption in our modeling experiments is that $100 \%$ of the freshwater drained from the Hudson Bay was transported to the four respective sites of release and that there was no mixing between freshwater and ocean water along the way. In reality, dynamic mixing of freshwater and ocean water could have occurred during transport. Since the ECBilt-CLIO-VECODE model has a coarse spatial resolution $\left(3^{\circ} \times 3^{\circ}\right)$ of the ocean component, it is not possible to simulate the detailed dynamic mixing process of freshwater and ocean water. Spence et al. (2008) investigated the sensitivity of the responses to a coarse spatial resolution model and an eddy-permitting resolution model for the $8.2 \mathrm{ka}$ event, and showed that responses of two models of coarse and fine spatial resolution are not significantly different. Therefore, the differential climatic responses we observe in our modeling experiments, particularly the distinctly different responses between the northerly $\mathrm{R} 1$ route and the three southerly routes, represent impacts due to different routing scenarios. Future work should focus on improving the spatial resolution of the climate model to adequately describe the topography of continental slopes along the drainage route and to characterize the dynamic dissipation of freshwater into the North Atlantic Ocean. This line of research will further refine our understanding of effective freshwater forcing to ocean circulation for different routes, especially the three southerly routing scenarios. Furthermore, additional detailed paleoceanographic proxy records from the Labrador Sea and northwestern North Atlantic Ocean are needed to provide further constraints on the freshwater drainage pathway.

\section{Summary and conclusions}

We have simulated four different routing scenarios of LAO drainage around $8.2 \mathrm{ka}$, with varying amounts of freshwater perturbation to examine the routing effects on climatic responses of freshwater perturbations to oceanic and atmospheric circulation. The modeling results suggest that changes in drainage routes could result in significantly different climatic responses and a southerly route of LAO freshwater drainage as suggested by oxygen-isotope data may be plausible. Overall, the modeling results show that a southerly routing scenario would lead to a weaker climatic anomaly than a northerly routing scenario.

In addition, our modeling results could provide insight into estimating the amount of freshwater drainage associated with the $8.2 \mathrm{ka}$ event. A southerly route would require more freshwater drainage than a northerly route in order to produce a similar climatic anomaly. Future research should focus on improving the spatial resolution of the climate model, incorporating dynamic mixing of freshwater and ocean water during the catastrophic freshwater drainage event, as well as collecting detailed paleoceangraphic proxy records to further constrain the freshwater drainage pathway.

Acknowledgements. Funding for this work was provided by the Earth System History program of the US National Science Foundation (OCE-0601814) and the McWilliams Fund of Tulane's Department of Earth and Environmental Sciences. We thank two anonymous reviewers and the journal editor U. Mikolajewicz for their constructive comments that helped improve the earlier versions of the manuscript.

Edited by: U. Mikolajewicz

\section{References}

Alley, R. B. and Ágústsdóttir, A. M.: The $8 \mathrm{k}$ event: cause and consequences of a major Holocene abrupt climate change, Quaternary Sci. Rev., 24, 1123-1149, 2005.

Alley, R. B., Mayewski, P. A., Sowers, T., Stuiver, M., Taylor, K. C., and Clark, P. U.: Holocene climatic instability - a prominent, widespread event 8200 yr ago, Geology, 25, 483-486, 1997.

Barber, D. C., Dyke, A., Hillaire-Marcel, C., Jennings, A. E., Andrews, J. T., Kerwin, M. W., Bilodeau, G., McNeely, R., Southon, J., Morehead, M. D., and Gagnon, J.-M.: Forcing of the cold event of 8,200 years ago by catastrophic drainage of laurentide lakes, Nature, 400, 344-348, 1999.

Bauer, E., Ganopolski, A., and Montoya, M.: Simulation of the cold climate event 8200 years ago by meltwater outburst from Lake Agassiz, Paleoceanography, 19, PA3014, doi:10.1029/2004PA001030, 2004.

Berger, A. and Loutre, M. F.: Insolation values for the climate of the last 10 million years, Quaternary Sci. Rev., 10, 297-317, 1991.

Brovkin, V., Bendtsen, J., Claussen, M., Ganopolski, A., Kubatzki, C., Petoukhov, V., and Andreev, A.: Carbon cycle, vegetation, and climate dynamics in the Holocene: experiments with 
the CLIMBER-2 model, Global Biogeochem. Cy., 16, 1139, doi:10.1029/2001GB001662, 2002.

De Vernal, A., Hillaire-Marcel, C., von Grafenstein, U., and Barber, D.: Researchers look for links among paleoclimate events, Eos Trans. AGU, 78, 247-249, 1997.

Ellison, C. R. W., Chapman, M. R., and Hall, I. R.: Surface and Deep Ocean Interactions During the Cold Climate Event 8200 Years Ago, Science, 312, 1929-1932, 2006.

Goosse, H. and Fichefet, T.: Importance of ice-ocean interactions for the global ocean circulation: A model study, J. Geophys. Res., 104, 23337-23355, doi:10.1029/1999JC900215, 1999.

Goosse, H., Selten, F. M., Haarsma, R. J., and Opsteegh, J. D.: Decadal variability in high northern latitudes as simulated by an intermediate-complexity climate model, Ann. Glaciol. 33, 525532,2001

Goosse, H., Renssen, H., Timmermann, A., and Bradley, R. S.: Internal and forced climate variability during the last millennium: a model-data comparison using ensemble simulations, Quaternary Sci. Rev., 24, 1345-1360, 2005.

Hillaire-Marcel, C., de Vernal, A., Bilodeau, G., and Wu, G.: Isotope stratigraphy, sedimentation rates, deep circulation, and carbonate events in the Labrador Sea during the last $\sim 200 \mathrm{ka}$, Can. J. Earth Sci., 31, 63-89, 1994.

Hillaire-Marcel, C., de Vernal, A., and Piper, D. J. W.: Lake Agassiz Final drainage event in the northwest North Atlantic, Geophys. Res. Lett. 34, L15601, doi:10.1029/2007GL030396, 2007.

Hughes, P. D. M., Blundell, A., Charman, D. J., et al.: An 8500 cal. year multi-proxy climate record from a bog in eastern Newfoundland: contributions of meltwater discharge and solar forcing, Quaternary Sci. Rev., 25, 1208-1227, 2006.

Keigwin, L. D., Sachs, J. P., Rosenthal, Y., et al.: The 8200 year BP event in the slope water system, western subpolar North Atlantic, Paleoceanography, 20, PA2003, doi:10.1029/2004PA001074, 2005.

Kendall, R. A., Mitrovica, J. X., Milne, G. A., Törnqvist, T. E., and Li, Y. X.: The sea-level fingerprint of the $8.2 \mathrm{ka}$ climate event, Geology, 36, 423-426, 2008.

Kerschner, H., Hertl, A., Gross, G., Ivy-Ochs, S., and Kubik, P. W.: Surface exposure dating of moraines in the Kromer valley (Silvretta Mountains, Austria)-evidence for glacial response to the $8.2 \mathrm{ka}$ event in the Eastern Alps?, The Holocene, 16, 7-15, 2006.

Kleiven, H. F., Kissel, C., Laj, C., Ninnemann, U. S., Richter, T. O., and Cortijo, E.: Reduced North Atlantic deep water coeval with the glacial Lake Agassiz freshwater outburst, Science, 319, 60-64, 2008.

Kobashi, T., Severinghaus, J. P., Brook, E. J., Barnola, J.-M., and Grachev, A. M.: Precise timing and characterization of abrupt climate change 8200 years ago from air trapped in polar ice, Quaternary Sci. Rev., 26, 1212-1222, 2007.

Lee, T.: Variability of the Gulf Stream path observed from satellite infrared images, Ph.D. thesis, Graduate School of Oceanography, University of Rhode Island, 1994.

LeGrande, A. N. and Schmidt, G. A.: Ensemble, water isotope-enabled, coupled general circulation modeling insights into the $8.2 \mathrm{ka}$ event, Paleoceanography, 23, PA3207, doi:10.1029/2008PA001610, 2008.

LeGrande, A. N., Schmidt, G. A., Shindell, D. T., Field, C. V., Miller, R. L., Koch, D. M., Faluvegi, G., and Hoffman, G.: Con- sistent simulations of multiple proxy responses to an abrupt climate change event, P. Natl. Acad. Sci. USA, 103, 837-842, 2006.

Leverington, D. W., Mann, J. D., and Teller, J. T.: Changes in the bathymetry and volume of glacial Lake Agassiz between 9200 and $7700{ }^{14} \mathrm{C}$ yr B.P., Quaternary Res., 57, 244-252, 2002.

Lutz, B., Wiles, G., Lowell, T., and Michaels, J.: The 8.2-ka event abrupt climate change event in Brown's Lake, northeast Ohio, Quaternary Res., 67, 292-296, 2007.

Manabe, S. and Stouffer, R. J.: Simulation of abrupt climate change by freshwater input to the North Atlantic Ocean, Nature, 378, 165-167, 1995.

Morrill, C. and Jacobsen, R. M.: How widespread were climate anomalies 8200 years ago?, Geophys. Res. Lett., 32(19), L19701, doi:10.1029/2005GL023536, 2005.

Opsteegh, J., Haarsma, R., Selten, F., and Kattenberg, A.: ECBILT: A dynamic alternative to mixed boundary conditions in ocean models, Tellus, 50, 348-367, 1998.

Rasmussen, S. O., Andersen, K. K., Svensson, A. M., Steffensen, J. P., Vinther, B. M., Clausen, H. B., Siggaard-Andersen, M.L., Johnsen, S. J., Larsen, L. B., Dahl-Jensen, D., Bigler, M., Rthlisberger, R., Fischer, H., Goto-Azuma, K., Hansson, M. E., and Ruth, U.: A new Greenland ice core chronology for the last glacial termination, J. Geophys. Res., 111, D06102, doi:10.1029/2005JD006079, 2006.

Raynaud, D., Barnola, J.-M., Chappellaz, J., Blunier, T., Indermuhle, A., and Stauffer, B.: The ice record of Greenhouse gases: a view in the context of future changes, Quaternary Sci. Rev., 19, 9-17, 2000.

Renssen, H., Goosse, H., and Fichefet, T.: Modeling the effect of freshwater pulses on the early Holocene climate: the influence of high-frequency climate variability, Paleoceanography, 17, 1-16, 2002.

Renssen, H., Goosse, H., Fichefet, T., and Campin, J.-M.: The 8.2 kyr BP event simulated by a global atmosphere-seaice-ocean model, Geophys. Res. Lett., 28, 1567-1570, 2001.

Renssen, H., Goosse, H., Fichefet, T., Brovkin, V., Driesschaert, E., and Wolk, F.: Simulating the holocene climate evolution at northern high latitudes using a coupled atmosphere-sea iceocean-vegetation model, Clim. Dynam., 24, 23-43, 2005.

Rohling, E. J. and Pälike, H.: Centennial-scale climate cooling with a sudden cold event around 8,200 years ago, Nature, 434, 975979, 2005.

Spence, J. P., Eby, M., and Weaver, A. J.: The sensitivity of the Atlantic meridionial overturning circulation to freshwater forcing at eddy-permitting resolutions, J. Climate, 21, 2697-2710, doi:10.1175/2007JCLI2103.1, 2008.

Teller, J. T., Leverington, D. W., and Mann, J. D.: Freshwater outbursts to the oceans from glacial Lake Agassiz and their role in climate change during the last deglaciation, Quaternary Sci. Rev., 21, 879-887, 2002.

Thomas, E. R., Wolff, E. W., Mulvaney, R., et al.: The 8.2 ka event from Greenland ice cores, Quaternary Sci. Rev., 26, 70-81, 2007.

Törnqvist, T. E., Bick, S. J., González, J. L., Van der Borg, K., and De Jong, A. F. M.: Tracking the sea-level signature of the 8.2 ka cooling event: New constraints from the Mississippi Delta, Geophys. Res. Lett., 31, L23309, doi:10.1029/2004GL021429, 2004.

Von Grafenstein, U., Erlenkeuser, H., Müller, J., Jouzel, J., and Johnsen, S.: The cold event 8200 years ago documented in oxy- 
gen isotope records of precipitation in Europe and Greenland, Clim. Dynam., 14, 73-81, 1998.

Wiersma, A. P., Renssen, H., Goosse, H., and Fichefet, T.: Evaluation of different freshwater forcing scenarios for the $8.2 \mathrm{kaBP}$ event in a coupled climate model, Clim. Dynam., 27, 831-849, doi:10.1007/s00382-006-0166-0, 2006.
Wiersma, A. P. and Renssen, H.: Model-data comparison for the 8.2 ka event: confirmation of a forcing mechanism by catastrophic drainage of Laurentide Lakes, Quaternary Sci. Rev., 25, 63-88, 2006. 